\title{
Childhood Tuberculosis: A Descriptive Study in the Pediatric Ward of a University Hospital in Abidjan
}

\author{
G. L. S. Couitchéré*, S. J. E. Enoh, G. B. Aka, L. Zaho, L. Cissé \\ Pediatric Department, Treichville University Hospital Center, Abidjan, Côte d'Ivoire \\ Email: ${ }^{\star}$ line.couitchere@gmail.com
}

How to cite this paper: Couitchéré, G.L.S., Enoh, S.J.E., Aka, G.B., Zaho, L. and Cissé, L. (2020) Childhood Tuberculosis: A Descriptive Study in the Pediatric Ward of a University Hospital in Abidjan. Open Journal of Pediatrics, 10, 206-216. https://doi.org/10.4236/ojped.2020.101020

Received: January 23, 2020

Accepted: March 21, 2020

Published: March 24, 2020

Copyright ( 2020 by author(s) and Scientific Research Publishing Inc. This work is licensed under the Creative Commons Attribution International License (CC BY 4.0).

http://creativecommons.org/licenses/by/4.0/ (c) (i) Open Access

\begin{abstract}
Introduction: Tuberculosis is one of the top ten causes of death in the world. Purpose: The purpose of this study was to describe the different locations of tuberculosis and the diagnostic means used in our department. Methods: This was a descriptive retrospective study of children under 15 years of age admitted in 2018 for tuberculosis. The variables under study were socio-demographic, clinical, paraclinical and evolutionary data Results: Forty-eight children were enrolled. The median age was 8.2 years $( \pm$ 4.5) and the M/F ratio was 1.4 . TB contamination was found in $20.8 \%$ of cases and the index was often a family member (80\%). The median diagnostic time was 49 ( \pm 33 ) days. Six patients had positive HIV serology, $82 \%$ had acute malnutrition and lung examination was abnormal in the majority of cases $(70.8 \%)$. Thorax-ray abnormalities were common (81\%) and tuberculin skin testing was positive in $70.6 \%$ of cases. The diagnosis was confirmed in $29.2 \%$ of the children and the confirmatory examinations were direct examination (9 cases), lymph node biopsy (4 cases) and rapid test (Expert $\mathrm{MTB} / \mathrm{RIF}$ ) (one case). In $70.8 \%$ of cases, this was a diagnostic presumption. Pulmonary tuberculosis accounted for $72.9 \%$ of which $39.6 \%$ multifocal forms and extra-thoracic form $27.1 \%$. Thirty-nine patients had received standard TB treatment and death occurred in $22.9 \%$ of cases. Conclusion: Children are a high-risk population for TB, especially in cases of family infection. Contacts screening through a systematic approach to diagnosis will reduce deaths. Diagnostic difficulties can be partly overcome by improving the accessibility of rapid testing.
\end{abstract}

\section{Keywords}

Tuberculosis, Child, Diagnosis 


\section{Introduction}

Tuberculosis is one of the top ten causes of death in the world. In 2016, 10.4 million people contracted the disease and 1.7 million died from it. More than $95 \%$ of deaths occur in low- and middle-income countries [1]. In 2016, 1 million children developed tuberculosis and 250,000 died from it [1]. It is estimated that the diagnosis and treatment of tuberculosis saved 53 million lives between 2000 and 2016 [1]. However, the high number of deaths is unacceptable given that most of them are preventable [1]. To put an end to the global TB epidemic, the WHO's strategy is to reduce the number of deaths by $95 \%$ and the incidence by 90\% between 2015 and 2035 [2]. The WHO strategy has several components, including early diagnosis and treatment of patients, systematic screening of contacts, preventive treatment of at-risk people and vaccination [2]. Recent advances were made in TB diagnostic methods. Since 2010, the WHO recommended the use of a rapid test (Expert MTB/RIF) for the diagnosis of pediatric tuberculosis and certain extra-pulmonary forms [1]. In Côte d'Ivoire, the average incidence of reported TB cases from 2001 to 2010 was 106 per 100,000 population. Child tuberculosis accounted for $4 \%$ - 5\% of cases diagnosed between 2002 and 2010 [3]. The main challenge in diagnosing tuberculosis in children is the difficulty of isolating Mycobacteria tuberculosis (MT). The lack of a standardized definition, the wide variety of clinical manifestations of the disease, the difficulties in diagnosing extra-pulmonary or atypical manifestations are existed. In particular, miliary TB and TB meningitis are major challenges. Moreover, the lack of priority given to childhood tuberculosis in national control programmes makes this task even more difficult [4] [5]. The objective of this study was to describe clinical presentations and diagnostic tools.

\section{Methods}

This descriptive retrospective study concerned children under 15 years of age hospitalized in the pediatric department of the Teaching Hospital of Treichville from 1 January to 31 December 2018 for tuberculosis treated with a regimen of anti-tuberculosis treatment standard.

Data from this study came from patients' medical records. The diagnosis of tuberculosis was made based on a bundle of arguments. These arguments were the tubercular contamination, the clinic, the tuberculin skin test, the $\mathrm{x}$-rays (chest x-ray, ultrasound), the search for AFB (resistant acid-alcoholic bacillus) by the Ziehl-Neelsen method [6] in different samples (spit, gastric aspiration fluid) or the histology of a biopsy (pleura, ganglion) and the use of the rapid test (MTB/RIF Expert).

Children with confirmed tuberculosis (BARR or rapid positive test or ganglionic histology showing tubercular granuloma) and children with typical tuberculosis (suggestive clinical and paraclinical signs) without diagnostic confirmation were included. Children with long-term fever isolated and children with TB contact with an X-ray image without clinical signs, all children with a posi- 
tive skin test with no suggestive clinical signs were excluded. Childhood tuberculosis included the pulmonary forms (involvement of pulmonary parenchyma and/or intrathoracic lymph nodes associated or not with extra-thoracic involvement) and the extra-thoracic forms (pleural, extra thoracic ganglionic, bony, joint, meningeal, abdominal and urogenital disorders) [5].

The variables studied were socio-demographic data (age, sex, place of residence), and anamnestic data (tubercular contamination, duration of signs evolution, chronology of signs, vaccination), physical signs, skin tests and paraclinical data (radiography, biology, pathology, immunology), HIV serology results, TB treatment, the evolution. Skin tests: IDR (intradermal reaction) was performed on tuberculin and was considered positive when the reaction was greater than or equal to 10 millimeters. HIV testing was done using PCR for children under 18 months and serology for children over 18 months. Nutritional status was assessed using weight/height indicators for children $0-5$ years of age and BMI (body mass index)/age for subjects aged six to 18.WHO Z-score classifications were used for the nutritional assessment of children (Standards- 2006) [7].

Data analysis: frequencies, means, medians were determined using STATA software version 14. The distribution of general signs between the age groups was compared using the chi2 test or exact Fisher's test when numbers were less than five. The values were considered statistically significant when $p<0.05$.

The agreement of the scientific committee of the hospital was obtained for the carrying out of this work during the session of the first quarter of 2019. The confidentiality of patients was respected.

\section{Results}

Demographic and Anamnestic Characteristics: Forty-eight children were diagnosed with tuberculosis; the prevalence of the disease was $1.17 \%$ in our department during the study year. The median age of patients was 8.2 years $( \pm 4.5)$, the age distribution was as follows: 0 - 4 years: 16 cases (33.3\%), 5 - 9 years: 16 cases (33.3\%), and $10-14$ years: 16 (33.3\%). The M/F ratio was 1.4. Twenty-eight patients (58.3\%) lived in Abidjan, of whom 15 (53.6\%) lived in precarious neighborhoods and seven (14.6\%) patients lived outside Abidjan.

BCG vaccine was given at birth in 10 children (20.8\%). Twenty-five (52\%) children were not in possession of their immunization records at the time of the consultation.

TB contamination was found in 10 patients (20.8\%), the index was a parent or sibling in eight cases (80\%). Eight children lived in the environment of a chronic cougher (16.7\%). The median duration of evolution of the main call sign prior to diagnosis was 49 ( \pm 33 ) days. Reasons for consultation were dominated by respiratory distress (39.6\%) and impairment of general condition (22.9\%), (Table 1).

\subsection{The Clinical Data}

The main general signs were fever $(93.8 \%$ or $\mathrm{n}=45)$, weight loss $(77.1 \%$ or $\mathrm{n}=$ $37)$, asthenia $(64.6 \%$ or $n=31)$ and night sweats $(45.8 \%$ or $n=22)$. There was no 
Table 1. Distribution of consultation reasons for children admitted to Treichville's Teaching Hospital for tuberculosis $(n=48)$.

\begin{tabular}{ccc}
\hline Characteristics & $\mathbf{n}$ & $\%$ \\
\hline Respiratory distress & 19 & 39.6 \\
Alteration of general condition & 11 & 22.9 \\
Abdominal distension & 8 & 16.7 \\
Chronic cough & 7 & 14.6 \\
Pneumopathy & 3 & 6.2 \\
\hline
\end{tabular}

significant difference in the distribution of general signs between different age groups for a given presentation (Table 2). Of the 39 patients with a nutritional status assessment, $32(82 \%)$ were malnourished, 21 (53.8\%) had severe acute malnutrition and 11 (28.2\%) had moderate malnutrition. Seven (17.9\%) children had normal nutritional status. Lung examination was abnormal in 34 patients (70.8\%). Tuberculin skin tests in 17 patients were positive in 12 cases $(70.6 \%)$ and negative in 3 cases (17.6\%); 2 patients (11.8\%) had TB anergia.

\subsection{The Paraclinical Examinations}

\subsubsection{Imaging}

The X-ray of the spine was abnormal (Figure 1) in the two patients who received it. Abdominal ultrasound was pathological in 12 patients $(85.7 \%)$ of the 14 patients who had done it. The abnormalities found in the ultrasound were ascites (10 cases) and adenopathies ( 4 cases). Standard chest $\mathrm{x}$-ray abnormalities found in $81 \%$ of cases ( 30 out of 37 patients who had them) were multiple, dominated by fluid (Figure 2) and/or gas pleural effusion (Table 3).

\subsubsection{Biology}

Retroviral serology was positive in six patients (12.5\%) and negative in 42 cases (87.5\%). Cytobacteriological examination of ascite fluid, pleural fluid and cerebrospinal fluid revealed lymphocytic-predominant hypercytosis in five cases and two cases respectively. Diagnostic confirmatory examinations were performed in 35 patients (72.9\%). Direct examination of gastric casing fluid was positive in nine cases (31\%) (Table 4). Lymph node biopsy in four patients (8.3\%) revealed TB-induced granulomatous adenitis.

Forms with confirmed diagnosis accounted for 29.2\% (14 cases) of which $20.8 \%$ (10 cases) were pulmonary tuberculosis and $8.4 \%$ were ganglionic. In $70.8 \%$ of cases, this was a diagnostic presumption.

Pulmonary tuberculosis accounted for $72.9 \%$ (35 cases) of which $39.6 \%$ were multifocal. The extra-thoracic form accounted for $27.1 \%$ (13 cases). The main extra-thoracic forms were ganglionic (four cases, i.e. 30.7\%, including 3 aged 1 to 4 years and the 4 th aged 10 years), peritoneal (four cases, i.e. $30.7 \%$, of which 3 were aged between 10 and 14 years and the 4 th were aged 6 years) and bone (tree cases, i.e. 23.1\%, including one case aged 4 years and two cases aged 
Table 2. Distribution of general signs by age groups and disease locations.

\begin{tabular}{cccccc}
\hline \multirow{2}{*}{ Symptoms } & Total & $1-5$ years & $6-10$ years & $11-15$ years & P value \\
\cline { 2 - 6 } & $\mathrm{N}=48$ & $\mathrm{~N}=16$ & $\mathrm{~N}=16$ & $\mathrm{~N}=16$ & \\
\cline { 4 - 6 } & $\mathrm{N}(\%)$ & $\mathrm{N}(\%)$ & $\mathrm{n}(\%)$ & $\mathrm{n}(\%)$ & \\
\hline Pulmonary tuberculosis & $16(33.3 \%)$ & $6(37.5 \%)$ & $4(25.0 \%)$ & $6(37.5 \%)$ & \\
Wever & $15(93.7 \%)$ & $6(100.0 \%)$ & $4(100.0 \%)$ & $5(83.3 \%)$ & \\
Asthenia & $12(75.0 \%)$ & $4(66.7 \%)$ & $3(75.0 \%)$ & $5(83.3 \%)$ & 1.00 \\
Night sweats & $9(56.3 \%)$ & $3(50.0 \%)$ & $2(50.0 \%)$ & $4(66.7 \%)$ & \\
Extrapulmonary tuberculosis & $13(27.1 \%)$ & $4(30.8 \%)$ & $5(38.4 \%)$ & $4(30.8 \%)$ & \\
Fever & $11(84.6 \%)$ & $4(100.0 \%)$ & $5(100.0 \%)$ & $2(50.0 \%)$ & 0.154 \\
Weight loss & $6(46.2 \%)$ & $3(75.0 \%)$ & $2(40.0 \%)$ & $1(25.0 \%)$ & 0.510 \\
Asthenia & $8(61.5 \%)$ & $3(75.0 \%)$ & $2(40.0 \%)$ & $3(75.0 \%)$ & 0.487 \\
Night sweats & $5(38.5 \%)$ & $2(50.0 \%)$ & $2(40.0 \%)$ & $1(25.0 \%)$ & 1.00 \\
Plurifocal forms & $19(39.6 \%)$ & $6(31.6 \%)$ & $7(36.8 \%)$ & $6(31.6 \%)$ & \\
Fever & $19100.0 \%)$ & $6(100.0 \%)$ & $7(100.0 \%)$ & $6(100.0 \%)$ & \\
Weight loss & $19(100.0 \%)$ & $6(100.0 \%)$ & $7(100.0 \%)$ & $6(100.0 \%)$ & \\
Asthenia & $14(73.7 \%)$ & $3(50.0 \%)$ & $6(85.7 \%)$ & $5(83.3 \%)$ & 0.431 \\
Night sweats & $12(63.2 \%)$ & $3(50.0 \%)$ & $4(57.1 \%)$ & $5(83.3 \%)$ & 0.594 \\
\hline
\end{tabular}

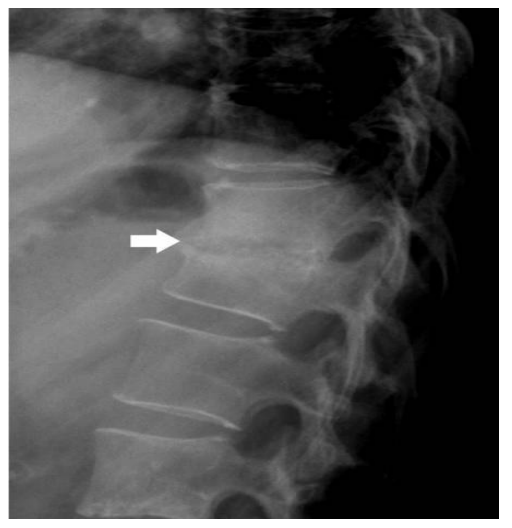

Figure 1. Spondylodiscitis (Pott's disease).

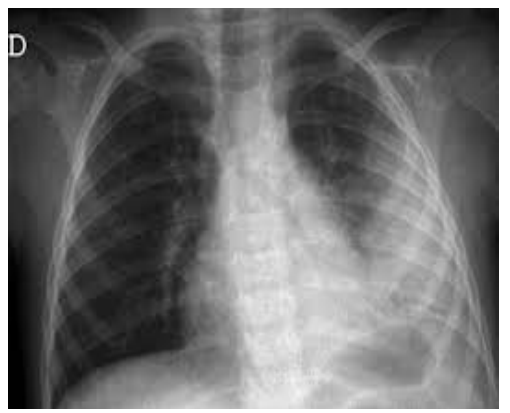

Figure 2. Medium-abundant left pleurisy. 
Table 3. Description of chest X-ray abnormalities $(n=37)$.

\begin{tabular}{ccc}
\hline Characteristics & $\mathbf{n}$ & $\%$ \\
\hline Normal & 7 & 14.6 \\
Alveolar syndrome & 6 & 12.5 \\
Mediastinal ganglion & 3 & 6.3 \\
Excavation & 3 & 6.3 \\
Intertitial syndrome & 5 & 10.4 \\
Hydropneumothorax & 3 & 6.3 \\
Pneumothorax & 4 & 8.3 \\
Pleurisy & 9 & 18.8 \\
Miliary & 4 & 8.3 \\
\hline
\end{tabular}

Table 4. Distribution of the results of specific biological examinations.

\begin{tabular}{|c|c|c|}
\hline Caracteristics & $\mathbf{n}$ & $\%$ \\
\hline \multicolumn{3}{|c|}{ Gene X-pert $(n=48)$} \\
\hline Positive & 1 & 2.1 \\
\hline Negative & 1 & 2.1 \\
\hline Notb performed & 46 & 95.8 \\
\hline \multicolumn{3}{|l|}{ AFB search $(n=48)$} \\
\hline Negative & 20 & 41.7 \\
\hline Positive & 9 & 18.7 \\
\hline Not performed & 19 & 39.6 \\
\hline \multicolumn{3}{|l|}{$\operatorname{CSF}(n=2)$} \\
\hline Not performed & 00 & 00.0 \\
\hline pathological & 2 & 100.0 \\
\hline \multicolumn{3}{|c|}{ Pleural fluid $(n=12)$} \\
\hline Pathological & 2 & 16.7 \\
\hline Normal & 2 & 16.7 \\
\hline Not performed & 8 & 66.6 \\
\hline \multicolumn{3}{|c|}{ Ascitic fluid $(n=10)$} \\
\hline Pathological & 5 & 50.0 \\
\hline Not performed & 5 & 50.0 \\
\hline
\end{tabular}

between 5 and 9 years). The over extra-thoracic forms were pleural (one case aged 8 years, i.e. $7.7 \%$ ) and meningeal (one case aged 5 years, i.e. 7.7\%).

Evolution: thirty-nine patients $(81.2 \%)$ received standard TB treatment (associating Rifampicin, Isoniazid, Pyrazinamide and Ethambutol), of which 25 (64.1\%) were diagnosed with presumption. In addition to the specific treatment, eight $(16.7 \%)$ children received corticosteroid therapy. The progression was fa- 
vorable in 33 patients (68.7\%) and 11 deaths (22.9\%) and four lost sight $(8.3 \%)$ were recorded. The lethality of HIV-infected subjects was $50 \%$. The median length of hospitalization was 19.7 days $( \pm 6.2)$.

\section{Discussion}

Child tuberculosis had a prevalence of $1.17 \%$ in the pediatric ward of the Teaching Hospital of Treichville in 2018. Côte d'Ivoire is at a high endemic level with an incidence of 106/100,000 inhabitants in 2010. The incidence of the disease in the zero to fourteen age group is not known, but children account for $4 \%$ to $5 \%$ of cases [3]. This proportion is significantly lower than the $15 \%$ expected in high-load countries [8], indicating under-diagnosis and under-notification of subjects under 15 years of age [4]. TB contamination was found in $20.8 \%$ of cases and in $80 \%$ of cases, the contaminator was a parent or sibling; however, no children in our population were seen for screening. One of the pillars of the WHO strategy to end the global TB epidemic [1] is the screening of contacts. Several authors reported contamination ranging from $27.5 \%$ to $83 \%$ and household contaminants ranging from $43.3 \%$ to $87.5 \%$ [9] [10] [11] [12]. The child's tuberculosis maintains the germ reservoir and the existence of the disease in the community [13].

Clinical aspects: The most common symptoms of pulmonary tuberculosis are fever and cough [14] [15] [16]. In our study, the most common general symptoms were fever $(93.8 \%)$, weight loss $(77.1 \%)$ and asthenia (64.6\%). The proportion of subjects with weight loss in the extra pulmonary form was relatively small and comparable to that of Snène et al. [17]. The above confirms the literature data on the rarity of weight loss in lymph node tuberculosis, which is the most common extra-thoracic form [18]. Some authors in proportions ranging from 50 to $73.6 \%$ [9] [19] also reported the acute malnutrition objectified in $82 \%$ of our patients. The incidence of extra-thoracic tuberculosis was close to that of all TB patients in Côte d'Ivoire. According to the national tuberculosis control program, the extra-pulmonary form represents $17 \%$ to $22 \%$ of reported cases [3]. Our results are also consistent with those of M'Pemba et al. who found pulmonary tuberculosis predominant [20], but contrary to the literature in general. In fact, in the last two decades, extra-thoracic tuberculosis seems to be increasing [21] and its relative frequency evaluated differently by the authors ranges from $48 \%$ to $83.3 \%$ [12] [17] [21] [22]. The most common location of extra thoracic tuberculosis is the lymph node, which accounts for $30 \%-67 \%$ of cases in the literature [17] [22] [23] and 30\% in our study. The clinical presentation of tuberculosis disease depends largely on the age of infection. Infants are more likely to develop miliary tuberculosis, while lymph node and meningeal tuberculosis is more common in small children of preschool age and finally, pleural and bone disease in older children [17]. In our study, the majority of children with lymph node tuberculosis ( 3 out of 4 children) and bone tuberculosis ( 2 out of 3 cases) were between one and four years of age, and between five and nine years of age, respectively. 
Paraclinical aspects: Diagnosis of TB can be difficult due to atypical symptoms that may result in delayed diagnosis. In this case, the bacteriological or histological confirmation remains the reference. Because of the paucibacillary nature of the child's disease, bacteriological evidence is infrequent. The proportion of patients with a smear positive for direct examination in our study (31\%) is in the range (14\% - 50\%) usually described [9] [17] [24] [25] [26] [27]. The culture is positive in $34 \%$ to $50 \%$ of childhood tuberculosis diseases [25] [26]. Lymph node tuberculosis is confirmed histologically in $50 \%$ to $75 \%$ of cases [17]. The four cases of lymph node tuberculosis included in this study were all confirmed histologically. To improve the diagnosis of tuberculosis, the WHO recommends several methods, including the use of the Xpert MTB/RIF [8] test. This test is recommended for the diagnosis of pulmonary and extra-thoracic tuberculosis. It can be used on samples of liquid or tissue products. Its sensitivity varies from $77 \%$ to $85 \%$ and its specificity from $95 \%$ to $100 \%$. However, an Xpert MTB/RIF negative test does not exclude tuberculosis [8] [23]. Only two children with pulmonary tuberculosis had benefited from this test whose cost limits its use. In accordance with the literature [9] [17] [20] [22] [24] [27], the majority of our patients had a presumptive diagnosis based on TB contamination, the clinic, the tuberculin skin test (TST), the chest x-ray. Although TST is an essential part of the diagnosis of tuberculosis in children, it can be falsely negative in $10 \%$ to $60 \%$ of cases of culture-positive tuberculosis [17] [23]. It lacks specificity due to its cross-reaction after vaccination by the BCG [17]. The positivity of tuberculosis skin test was $70.2 \%$ in our study and a TB anergia was noted in $11.8 \%$ of children with suggestive clinical signs. During childhood tuberculosis disease, radiological abnormalities of the chest are frequent and variable [26]. Radiographic abnomalies were observed in proportions superimposed on those of Adonis-Koffy et al with predominance of pleural effusion [27].

Evolutionary aspects: In high-incidence countries, treatment of tuberculosis is generally initiated based on a presumptive diagnosis, as was the case for the majority (64.1\%) of the children included in the study [28] [29]. The trend was marked by a death rate of $22.9 \%$. Randriatsarafara and al reported a fatality of $18 \%$ [19]. M'Pemba and Segbedji had rates of $1.4 \%$ and $4 \%$ respectively, mainly among subjects with TB/HIV co-infection [20] [24]. This high lethality could indicate a delay in objective testing by a median diagnostic delay of 49 ( \pm 33 ) days, a significant proportion of plurifocal forms and the existence of comorbidities (HIV infection, malnutrition). The reduction of deaths will require contact screening through a systematic approach to diagnosis (based on a clinical algorithm associated with a chest $\mathrm{x}$-ray). The clinical algorithm will take into account the most common general signs, the existence of lung signs or other suggestive signs. It is essential to improve the accessibility of the rapid test to facilitate the diagnosis of extra-thoracic forms. In order to achieve this, the national $\mathrm{TB}$ programme must give priority to childhood $\mathrm{TB}$ as recommended by the WHO [5].

Our results must be qualified. This is a retrospective study with a high risk of 
bias. In addition, the rate of completion of specific examinations is low. This contributes to overestimating or underestimating the respective frequencies of the forms of pulmonary and extra thoracic tuberculosis and even of the forms with diagnostic confirmation. Despite these limitations, this work provides relevant information that has made it possible to make recommendations to promote early diagnosis.

\section{Conclusion}

Pulmonary tuberculosis is common in children in our country. Lymph node tuberculosis represents the main form of extra-thoracic tuberculosis, which accounts for about a third of the cases included in this study. Due to the paucibacillary nature of the disease in children, the diagnosis is mainly a presumptive diagnosis based on tubercular contamination and compatible clinical signs, evocative radiographic abnormalities, a positive TST. Lethality is high due to lack of screening of children, late diagnosis and comorbidities. The popularization of the rapid test recommended by the WHO in children will help improve the diagnosis. Contacts screening through a systematic approach to diagnosis will reduce deaths.

\section{Conflicts of interest}

The authors declare no conflict of interest regarding the publication of this paper.

\section{References}

[1] OMS. Tuberculose: Principaux faits. https://www.who.int/fr/news-room/fact-sheets/detail/tuberculosis

[2] OMS. Stratégies de l'OMS pour mettre fin à la tuberculose: Cibles et indicateurs. https://www.who.int/tb/strategy/end-tb/fr

[3] Côte d'Ivoire. Plan stratégique national 2012-2015 de lutte contre la tuberculose. http://www.nationalplanningcycles.org/sites/default/files/countrydocs/CoteDIvoire/ pns 2012-2015 tb.pdf

[4] World Health Organization (2011) Global Tuberculosis Report 2011. World Health Organization, Geneva.

[5] World Health Organization (2014) Guidance for National Tuberculosis Programmes on the Management of Tuberculosis in Children. World Health Organization, Geneva.

[6] Technique de coloration des mycobactéries. https://microbiologiemedicale.fr/coloration-mycobacteries-ziehl-auramine

[7] The WHO Child Growth Standards. http://www.who.int/childgrowth/standards/en

[8] Bonnes Pratiques de dépistage et de traitement de la tuberculose: Réflexions et enseignements tirés de l'Afrique de l'Ouest et du Centre et d'ailleurs.

https://www.theglobalfund.org/media/8274/core wca-tb-best-practices technicalbri ef fr.pdf

[9] Soumana, A., Kamaye, M., Ngoumboute, I., Dima, H., Daouda, B. and Guero, T. 
(2016) La tuberculose chez l'enfant: A propos de 29 cas colligés dans deux hôpitaux de Niamey et au centre national antituberculeux. Mali Médical, 31, 1-8.

[10] De Pontual, L., Hollebecque, V., Bessa, Z. and Muller, M.H. (2004) Enquête sur la tuberculose pédiatrique en Seine Saint Denis: Les moyens qui ont permis le contrôle de la recrudescence. The International Journal of Tuberculosis and Lung Disease, 8 , 976-981.

[11] Mabiala-Balela, J.R., Makosso, E., Nzingoula, S. and Senga, P. (2005) Aspects radiologique du mal de Pott chez l'enfant: A propos de 92 cas. Bulletin de la Société de Pathologie Exotique, 98, 14-17.

[12] Monia, K., Aymen, L., Samia, Z., Aida, B., Fafani, B.M., Faical, O., Faouzia, K. and Sihem, B. (2009) La tuberculose de l'enfant: Aspects cliniques et problèmes diagnostiques à propos de 30 observations. La Tunisie médicale, 87, 61-67.

[13] Hamzaoui, A. (2015) La tuberculose de l'enfant. Revue de pneumologie clinique, 71, 168-180. https://doi.org/10.1016/j.pneumo.2014.03.006

[14] Jaganath, D., Zalwango, S., Okware, B., Nsereko, M., Kisingo, H., Malone, L., et al. (2013) Tuberculosis Research Unit. Contact Investigation for Active Tuberculosis among Child Contacts in Uganda. Clinical Infectious Diseases, 57, 1685-1692. https://doi.org/10.1093/cid/cit645

[15] Rigouts, L. (2009) Clinical Practice: Diagnosis of Childhood Tuberculosis. European Journal of Pediatrics, 168, 1285-1290. https://doi.org/10.1007/s00431-009-0988-y

[16] Andersen, P.H., Thomsen, V.O. and Smith, E. (2001) Tuberculosis among Children in Denmark, 1990-1999. Ugeskr Læger, 163, 6739-6742.

[17] Snène, H., Berraies, A., Hamdi, B., Ammar, J., Ouali, H. and Hamzaoui, A. (2016) Tuberculose de l'enfant: Une étude descriptive dans un service de pneumo-pédiatrie en Tunisie. La Tunisie Médicale, 94, 259-264.

[18] Ben M'hamed, R., Hachicha, H. and Zgolli, C. (2013) La tuberculose lymphonodale cervicale chez les enfants vaccines par le BCG. Journal de la Société Tunisienne d'ORL, 30, 61-63.

[19] Randriatsarafara, F.M., Vololonarivelo, B.E., Rabemananjara, N.N., Randrianasolo, J.B., Rakotomanga, J.D. and Randrianarimanana, V.D. (2014) Facteurs associés à la tuberculose au centre hospitalier Mère-Enfant de Tsararalana, Antanarivo: Une étude cas-témoins. Pan African Medical Journal, 19, 224.

https://doi.org/10.11604/pamj.2014.19.224.4676

[20] M'Pemba, A.B., Loufoua, L., Youndouka, J.M., Pambou, B. and Nzingoula, S. (2008) La tuberculose chez l'enfant au CHU de Brazzaville de 1995 à 2003. Bulletin de la Société de Pathologie Exotique, 101, 303-304. https://doi.org/10.3185/pathexo3092

[21] Maltezou, H.C., Spyridis, P. and Kafetziz, D.A. (2000) Extrapulmonary Tuberculosis in Children. Archives of Disease in Childhood, 83, 342-346. https://doi.org/10.1136/adc.83.4.342

[22] Folquet, A.M., Gauze, J.C., Kouakou, K.C., Dainguy, M.E. and Diomande, D. (2006) Miliaire tuberculeuse chez l'enfant. A propos 89 cas colligés au Centre anti-tuberculeux d'Adjamé. Mali Medical, 21, 15-18.

[23] Jabri, H., Lakhdar, N., El Khattabi, W. and Afif, H. (2016) Les moyens diagnostiques de la tuberculose. Revue de Pneumologie Clinique, 72, 320-325. https://doi.org/10.1016/j.pneumo.2016.06.003

[24] Segbedji, K.A., Djadou, K.E., Tchagbele, O.B., Kpegouni, M., Bessi Kama, L.K., Azoumah, K.D. and Agbèrè, A.D. (2016) Tuberculose de l'enfant au Togo: Aspects épidémiologiques, diagnostiques, thérapeutiques et évolutifs. Medecine et Sante 
Tropicales, 26, 318-322. https://doi.org/10.1684/mst.2016.0593

[25] Prévention et prise en charge de la tuberculose en France (2003) Particularités de la tuberculose pédiatrique. Revue des Maladies Respiratoires, 20, 7S52-7S55. http://www.em-consulte.com $>$ rmr $>$ revue $>$ rmr $>2003$

[26] Delacourt, C. (2011) Particularités de la tuberculose chez l'enfant. Revue des Maladies Respiratoires, 28, 529-541. https://doi.org/10.1016/j.rmr.2010.10.038

[27] Adonis-Koffy, L., Kouassi, F. and Timité-Konan, A.M. (2004) Analyse des critères diagnostiques de la tuberculose de l'enfant en milieu ivoirien hospitalier. Bulletin de la Société de Pathologie Exotique, 97, 127-128.

[28] Lighter, J. and Rigaud, M. (2009) Diagnosing Childhood Tuberculosis: Traditional and Innovative Modalities. Current Problems in Pediatric and Adolescent Health Care, 39, 61-88. https://doi.org/10.1016/j.cppeds.2008.12.003

[29] Starke, J.R. (2007) New Concepts in Childhood Tuberculosis. Current Opinion in Pediatrics, 19, 306-313. https://doi.org/10.1097/MOP.0b013e32814b164a 